\title{
DESCASO COM O PLANEJAMENTO DEIXA O PAÍS SEM RUMO
}

Coluna publicada em 22.9.2015: <http://www.conjur.com.br/2015-set-22/ contas-vista-descaso-planejamento-deixa-pais-rumo $>$

A apresentação da proposta orçamentária da União para o exercício de 2016, realizada em 31 de agosto de 2015, ${ }^{1}$ foi a principal notícia dos últimos dias, especialmente pelo inusitado fato de ter sido encaminhada com a previsão de déficit, o que teria precipitado a queda do Brasil em ranking de agência de classificação de risco. É importante constatar e destacar que, em situações como essa, se percebe a real importância do orçamento público para o país e a vida das pessoas.

Porém, o que chama ainda mais a atenção é justamente um fato para o qual não se deu nenhum destaque, ocorrido no mesmo dia: ${ }^{2}$ a apresentação do Plano Plurianual (PPA) da União para o período 2016-2019, que atualmente é o principal instrumento jurídico de planejamento governamental. Ofuscado pelas notícias sobre o orçamento, o PPA, documento responsável pela definição dos rumos do país para os próximos quatro anos, acabou sendo deixado de lado. ${ }^{3}$

Poucos viram o documento que foca as ações do governo em "desenvolvimento, produtividade e inclusão social", estabelecendo as diretrizes estratégicas de médio prazo, e que deve - ou deveria - balizar todas as ações governamentais. E, atualmente, em face da ausência de planos nacionais, acaba direcionando as ações dos demais entes federados, dado nosso federalismo cooperativo em que os entes subnacionais guardam forte dependência dos recursos concentrados no governo federal. Um documento que requer, mais do que a formalidade de ser aprovado por

1 Nos termos em que determina a Constituição - ADCT, artigo 35, $\$ 2^{\circ}$, III.

2 Também por determinação Constitucional - ADCT, artigo 35, $\$ 2^{\circ}$, I.

3 Uma das poucas referências está na curta notícia publicada pelo jornal Valor Econômico em 31 de agosto de 2015: Plano Plurianual foca em educação, inclusão e redução de desigualdades. 
lei após ser analisado pelo Congresso Nacional nos próximos quatro meses, uma efetiva demonstração, por parte do governo, de que será levado a sério - o que não parece estar ocorrendo, dada a pouca atenção que lhe tem sido dispensada. Indício claro de que não terá qualquer efeito para os fins que justificam sua existência.

Uma lamentável constatação do que já é público e notório: o descaso com o qual se tem tratado o planejamento das ações governamentais nos últimos anos. Falha que seguramente é uma das principais - se não a principal - responsáveis pelo descalabro fiscal e má gestão pública que se vê presente atualmente.

Inúmeros atos se somam de modo a não deixar dúvidas sobre o desprezo que este governo, principalmente no âmbito federal, tem pelo planejamento.

A começar pelo pífio plano de governo apresentado pela atual presidente por ocasião do registro de sua candidatura à reeleição, ${ }^{4}$ um documento por demais simples, vago e pouco específico, o que é injustificável para quem estava no comando do governo federal havia quase quatro anos, com todas as condiçóes para detalhar com precisão e riqueza de detalhes o que pretenderia fazer ao assumir um segundo mandato.

Em junho do ano passado, tivemos uma das poucas boas notícias em matéria de planejamento, com a aprovação, quatro anos atrasada, da lei do Plano Nacional de Educação (Lei 13.005, de 25 de junho de 2014), que, se espera, seja seguida com atenção, rigor e de forma prioritária, especialmente quando se anuncia como lema de governo o "Pátria Educadora". No entanto, a segurança quanto a isso começa a ruir quando o ministro da Educação nomeado dura poucos meses no cargo e é substituído, gerando insegurança quanto à gestão do setor.

E, em junho deste ano, esgotou-se o prazo para que estados e municípios apresentassem os respectivos planos estaduais e municipais, e muitos entes federados ainda não cumpriram a determinação legal, dificultando a gestão cooperativa dessa área, comprometendo a fiel execução do plano.

Paralelamente, o lema da "Pátria Educadora" é protagonizado não pelo Ministério da Educação, mas pela Secretaria de Assuntos Estratégicos, ${ }^{5}$ e veem-se previstas iniciativas na mesma política pública por órgãos diversos e por instrumentos diferentes, gerando uma desorganização administrativa que compromete todo o funcionamento da máquina estatal. E já se noticia que o governo decidiu "engavetá-lo", antes mesmo de ter sido implantado: "O Palácio do Planalto decidiu

Planos de governo são essenciais para a escolha do próximo presidente, nesta edição, p. 129-134.

5 BRASIL. SAE. Pátria educadora: a qualificação do ensino básico como obra de educação nacional. Brasília, abril de 2015. 
manter engavetado o projeto 'Pátria Educadora', mote do segundo mandato da presidente Dilma Rousseff, que até hoje não saiu do papel. O plano, lançado no discurso de posse da presidente, foi elaborado pelo ministro da Secretaria de Assuntos Estratégicos (SAE), Mangabeira Unger, e prevê metas na área educacional. Mas uma disputa de protagonismo político entre Mangabeira e o ministro da Educação Renato Janine Ribeiro, na prática inviabilizou sua implementação". ${ }^{6}$ Recentemente, saiu do cargo o ministro responsável pela Secretaria de Assuntos Estratégicos e idealizador do plano, o que deve sepultá-lo de vez. Com previsōes para organizar a estrutura de cooperação federativa na educação, é mais um prejuízo à gestão daquela que foi anunciada como a área prioritária do governo. Fatos lamentáveis, exigindo que a sociedade organize-se para exercer um efetivo controle social sobre o cumprimento das metas e estratégias nele fixadas, cobrando a fiel execução do plano.

Mas não é só. Pouco antes da apresentação das propostas de lei orçamentária e do plano plurianual, leis que formalmente regem o planejamento governamental e que deverão ser submetidas à apreciação do Congresso Nacional, surge a "Agenda Brasil", por iniciativa do presidente do Senado, com medidas de diversas naturezas, voltadas a pautar a ação governamental nos próximos anos, que se alteraram no decorrer de poucos dias, e já quase não se fala mais no assunto. ${ }^{7} \mathrm{E}$, com isso, cada vez menos se sabe quais são os objetivos que o país pretende alcançar, os meios para fazê-lo e quem os define.

O descaso não termina aí. Por ocasião da apresentação da proposta orçamentária deste ano, surpreendem as notícias informando ter sido decidido na véspera, um domingo, que haveria a previsão de déficit e respectivo montante: "Depois de desistir de recriar a CPMF, o governo decidiu neste domingo (30) encaminhar ao Congresso sua proposta de Orçamento da União para o próximo ano com uma previsão de déficit primário (...) $\mathrm{O}$ tamanho do déficit estava sendo definido na noite de domingo e ainda passará por uma última análise nesta segunda-feira (31), quando a proposta precisa ser enviada ao Congresso". ${ }^{8}$

É absolutamente injustificável e inaceitável que decisões dessa importância, envolvendo bilhōes de reais e sobre os assuntos mais relevantes, sejam tomadas de inopino, na véspera, deixando clara a total falta de compromisso com o planejamento; principalmente porque a lei orçamentária é apenas a parte final de todo um proces-

6 Planalto paralisa mote do $2^{\circ}$ mandato. O Estado de S.Paulo, 13 de setembro de 2015. No mesmo sentido, a notícia de 15 de setembro, Impasse e caos na educação.

7 <www12.senado.leg.br/noticias/materias/2015/08/12/agenda-brasil>.

8 Dilma manda orçamento ao Congresso com déficit. Folha de S.Paulo, 31 de agosto de 2015. 
so de planejamento governamental e se insere no contexto de um ordenamento jurídico que deve ser coeso, respeitando-se o Plano Plurianual vigente e a Lei de Diretrizes Orçamentárias (LDO), ser coeso, devendo a Lei Orçamentária guardar coerência com o Plano Plurianual e a Lei de Diretrizes Orçamentárias (LDO), que precedem.

E na Lei de Diretrizes Orçamentárias, proposta em abril para ser aprovada até o final de junho, devem estar previstos, no anexo de metas fiscais, as metas relativas a receitas, despesas, resultados nominal e primário e o montante da dívida pública. ${ }^{9}$ O projeto apresentado - que até o momento não foi aprovado, em desacordo com o que estabelece a legislação vigente - fez constar previsão de superávit primário no montante de $\mathrm{R} \$ 104$ bilhões para o governo central e $\mathrm{R} \$ 126$ bilhōes para o setor público (art. $2^{\circ}$ do projeto).

Agora, quatro meses depois, é apresentado o projeto de lei orçamentária em desacordo com o projeto de LDO. E poucos dias após ser apresentado o projeto de lei orçamentária deficitário, ante a repercussão negativa, já se fala em alterar a previsão de déficit, com propostas de novas fontes de receita, como a recriação da CPMF, que havia sido expressamente descartada alguns dias antes. E pasmem! Em decisões tomadas, novamente, no domingo da véspera: "O anúncio, que foi objeto de reuniōes no fim de semana e será amarrado após um encontro de ministros na manhã desta segunda, é a primeira resposta às cobranças do mercado por ter enviado um Orçamento com déficit, medida que levou a agência Standard \& Poor's a tirar o selo de bom pagador do país no dia 9, agravando a crise". ${ }^{10}$

É assustador pensar que decisões fundamentais para o país, que deveriam ser objeto de estudos profundos, bem elaborados, submetidos à reflexão e discussão qualificadas, foram tomadas enquanto a Ponte Preta goleava o Santos e Faustão apresentava suas videocassetadas. Simplesmente inacreditável.

Tudo leva a crer que os desmandos em matéria orçamentária ocorridos no final do ano passado, especialmente no que se refere ao desrespeito ao sistema de planejamento orçamentário, estão para se repetir. Presenciamos pela primeira vez uma LDO modificada no final do ano, com a alteração da previsão da meta de superávit primário, apenas para evitar seu formal descumprimento; e a LDO do ano em curso foi aprovada com mais de seis meses de atraso, já no exercício seguinte, como expus na coluna $O$ direito financeiro precisa ser levado a sério, e 2015 começou mal, nesta edição, p. 183-188. Escrevi, à época, que é "difícil saber, a essa altu-

9 Lei de Responsabilidade Fiscal - LRF (Lei Complementar 101, de 2000), art. 4º, I, a e $\$ 1^{\text {o }}$.

10 Dilma prepara corte superior a R\$ 22 bi. Folha de S.Paulo, em 14 de setembro de 2015 
ra, o que poderá ser feito para surpreender, pois a impressão é que todos os limites da improvisação e desconsideração total pelo ordenamento jurídico em matéria financeira foram ultrapassados". Pelo que se vê, não demoramos para descobrir...

No final deste mês, a maior parte dos estados da federação deve apresentar seus respectivos planos plurianuais. Espera-se que não sigam o exemplo do governo federal, e elaborem um documento que, além de sério, consistente e bem elaborado, dê demonstrações inequívocas que será o guia da administração pública estadual pelos próximos quatro anos.

Há dois anos, ao tratar da apresentação das propostas de planos plurianuais municipais, ponderei que "governar um município sem um Plano Plurianual sério, bem elaborado, precedido de estudos de cenários internos e externos, com escolhas criteriosas e democráticas de prioridades, fixando estratégias claras e bem definidas, é como comandar um transatlântico no meio do oceano sem mapa, instrumentos de navegação e, principalmente, sem saber o porto de destino. Pouco importa cuidar da adequada limpeza, funcionamento da cozinha, da casa de máquinas e tudo o mais que é necessário, se o navio está verdadeiramente à deriva, pois o comandante nem sequer sabe para onde vai". ${ }^{11}$ Muito mais grave é governar um país de dimensões continentais como o nosso, onde não deveria haver espaço para o improviso, que parece estar sendo adotado como verdadeiro método de administração.

Os fatos estão deixando cada vez menos dúvida de que o comandante (ou seria comandanta?) não tem a menor ideia da rota a seguir, talvez nem saiba onde está. Não é nada bom estar dentro de um navio à deriva. Os icebergs estão por aí, a qualquer momento pode-se deparar com um deles no caminho, sem tempo de desviar.

11 Planejamento municipal precisa ser levado a sério, nesta edição, p. 135-138. 
